\title{
Medical error reporting among physicians and nurses in Uganda
}

\author{
Gideon Mauti, Margaret Githae
}

The Catholic University of Eastern Africa, Community Health and Development.

\begin{abstract}
: patients at risk. Medical error reporting systems could help reduce the errors. influencing error reporting. methods. prove medical error reporting among nurses and physicians respectively. errors should not be punished.

Keywords: Medical error reporting, physicians, nurses, Uganda.

DOI: https://dx.doi.org/10.4314/ahs.v19i4.33 bttps:/ / dx.doi.org/10.4314/abs.v19i4.33

\section{Introduction}

Patient safety is the most fundamental component of health care quality ${ }^{1}$ and it is a priority for every health care system in ensuring and improving the quality of health care. The Institute of Medicine defines it as "freedom from accidental injury because of medical care or medical errors". This includes delivering responsible care by preventing unnecessary injury to patients as far as possible ${ }^{2}$. Rather than blaming healthcare workers for the errors, systems that document, reduce or prevent the errors from occurring should be created, since "to err is hu man", ${ }^{3}$.
\end{abstract}

Background: Patient safety is a fundamental component of health care quality and medical errors continue to occur, placing

Purpose: This study assessed "Medical error reporting among Physicians and Nurses in Uganda". The objectives were; (1) identify the existing medical error reporting systems. (2) Assess the types of medical errors that occurred. (3) Establish factors

Methods: A cross-sectional, descriptive study in Kisubi and Entebbe hospitals between March to August 2013, with quantitative

Results: Medical errors occurred in the two hospitals (53.2\%), with overdoses (42.9\%) leading. Neither hospital had a medical error reporting system. More than two thirds, 42(64.6\%), would not report. Almost half, 29(44.6\%) believe reporting a medical error is a medical obligation. Majority, 50(76.9\%), believed the law does not protect medical error reporting. Not punishing health workers who report medical errors, $(53.8 \%)$ and 'training on error reporting $(41.70 \%)$ are the greatest measures to im-

Conclusion: Medical errors occur in the two hospitals and there are no reporting systems. Health workers who report medical

Cite as: Mauti G, Githae M. Medical error reporting among physicians and nurses in Uganda. Afri Health Sci.2019;19(4):3107-3117.

Medical error reporting systems are still rare in healthcare systems, though such systems have fairly been established in some countries ${ }^{4}$.

Efforts in medical error reporting in Uganda spearheaded

\section{Corresponding author: \\ Gideon Mauti, \\ The Catholic University of Eastern Africa, \\ Community Health and Development. \\ Email:gmauti@cuea.edu, gideonscareer@rocketmail.com}

by the National pharmacovigilance through the National Drug Authority have recently made attempts to record and report medical errors. These reports have mainly focused only on a few drug related adverse effects and maternal audits, leaving other medical errors underreported.

Despite reporting been identified as an important aspect inensuringthesafetyofpatients ${ }^{5}$, no system is perfect and for that matter a health system as that of a developing country, such as Uganda will not be an exception. Notwithstanding that, frantic efforts are to be made at all levels to ensure an adequate and perfect system. If not addressed, patients will lose trust in health service provision, driving them into unconven tional risky healthcare options and discourage innovation. This will lead to deterioration of the quality of health service delivery and continue affecting patient safety with many near misses, adverse events and prescription errors.

Without reporting of the medical errors, more burdens will be added to individuals, families and the community socio-economically, through deaths and incapacitation.

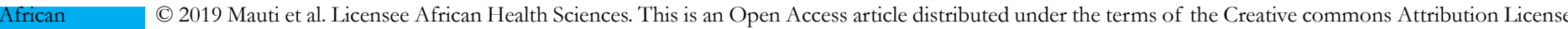
(https://creativecommons.org/licenses/BY/4.0), which permits unrestricted use, distribution, and reproduction in any medium, provided the original work is properly cited.
} 
Despite the state of underreporting, there is little information on factors influencing the recording and reporting of medical errors in Uganda. If not known, the health management information system (HMIS) will not address the problem of medical errors. Determining the factors influencing medical error reporting can result in taking appropriate managerial and individual measures to increase error reporting, decrease the occurrence of these errors and improve patient outcomes. Therefore, the findings of this study will help in improving patient safety and assist policy makers in formulating and implementing medical error reporting policies.

The primary objective was to study the occurrence and factors influencing medical error reporting among physicians and nurses in Kisubi and Entebbe hospitals. To answer the main objective, the study sought to: identify the existing medical error reporting systems; assess the types of medical errors that occurred and establish the factors influencing error reporting in Entebbe and Kisubi hospitals.

\section{Methodology}

\section{Study setting, design and sampling}

This study analyzed the existence of medical error reporting systems, investigated the types of errors that occurred and established factors that influence medical error reporting in the hospitals. This was across-sectional, descriptive study design with quantitative data collection approaches. The research design was to ensure that the evidence was obtained to enable the researcher to answer the initial question as unambiguously as possible (Yin, 1989). The study hospitals were purposively selected, with Entebbe hospital as a public hospital and Kisubi hospital as a Private Not for Profit hospital. This was to ensure comparison of reporting practices between public and private hospitals. The population of staff was 109 in Entebbe and 76 in Kisubi hospital. Total population was 185. Of these, 167 were nurses and 18 physicians. However, the management reported that approximately half of the nurses were usually on duty per shift (day or night). Hence the total nurse population was divided by two, to give a total of 83 . The total population under study was therefore (83 nurses +18 physicians), 101 .

In determining the sample size, Fishers two stage formula was applied since the sample population was less than10,000 (Fisheretal1998). Using a standard devia- tion (1.96) and a population proportion (0.5), a sample size (n)384 was calculated. The sample was then adjusted using the formula: $\mathrm{NF}=\mathrm{n} /\{1+(\mathrm{n} / \mathrm{N})\}$ to find a final sample size $(\mathrm{NF})$ of 80 . The sample was stratified by cadre according to physicians and nurses. All physicians were included. The remaining 62 were nurses. Nurses were further proportionately distributed per hospital using a percentage of total nurse staffing levels. The sample consisted of 47 respondents from Entebbe hospital, including 10 physicians and 37 nurses and 33 respondents from Kisubi hospital, including 8 physicians and 25 nurses. In total, 80 study participants were selected in the study. The unit of analysis was a physician and a nurse in the hospital who fulfilled the inclusion criteria.

Study participants were stratified by cadre into nurses and physicians. They were then proportionately distributed per the hospital population. The study hospitals were chosen purposively so as to compare factors influencing medical error reporting between public and private hospitals. Kisubi hospital is one of the oldest private not for profit and fourth largest hospital (after Mulago and Butabika) in Uganda under Uganda Catholic Medical Bureau (UCMB). It is also the oldest hospital in the country and offering health care to millions of people. Entebbe General Hospital is a public / government hospital in Wakiso district. It is a major referral facility for Busiro South and surrounding areas like Entebbe and Kyadondo South districts

\section{Data collection}

Every respondent filled in a self-administered questionnaire. Through questionnaires, socio-demographic characteristics, information on the existence of error reporting systems, the types of errors occurring/captured in the systems and the duration of existence of error reporting system was collected. In addition, the attitude and knowledge of physicians and nurses on error reporting as well as their views on factors that discourage reporting of errors, perception about medical error reporting and measures which can help to improve reporting of errors were explored using questionnaires. Records were reviewed to establish the existing error reporting systems. To be included as a study subject, one had to be a physician or a nurse in the hospital (either permanently em

ployed, visiting/temporarily employed). Anybody who was neither a physician nor a nurse and those who did not consent/ not willing to participate in the interview wereexcluded. In addition, patients who were below18 years 
or above 45 years and records older than 2012, when traced backwards were excluded.

\section{Data analysis}

Quantitative data was analyzed using SPSS version16.0. Descriptive statistics was done to identify the basic features of the data (frequency distribution and means). Statistical significance was declared at $\mathrm{P}<0.05$. Frequency distributions and percentages were calculated for each factor. This process contributed to meeting the 'descriptive' objectives, and guided further data collection, including the development of interview schedules.

\section{Ethical consideration}

Study ethical clearance was obtained from Kampala University, Graduate school, Department of health science. Permission to carry out the study in the selected study hospitals was sought from the respective hospitals and signed authorization given by hospital administration. In- formed consent was sought from each respondent, and the right of withdrawal at any point of the study clearly explained. The respondents were assured that information they provided was confidential.

\section{Results}

The respondent's socio-demographic characteristics are shown in table 1 . The study response rate was $84.6 \%$ response. Most respondents, 19,(45.50\%), were aged between 25-30 years. Generally, majority of respondents, were females, representing 34, (73.9\% ) and $22(71.00 \%)$ of staff in Entebbe and Kisubi hospitals respectively. Majority of the respondents, 39(84.4\%), were nurses.

Majority of the nurses, $28(73.8 \%)$ had attained a certificate as the highest level of education. About a quarter, $15(23.1 \%)$ had a diploma level of education while only 2 $(3.1 \%)$ of the sampled nurses had a degree level of education. All physicians, 12(100.0\%), had attained a degree as the highest level of education, (table 1).

Table 1. Socio-demographic characteristics

\begin{tabular}{|c|c|c|c|c|}
\hline \multicolumn{2}{|l|}{ Age of respondents } & $\begin{array}{l}\text { Entebbe } \\
\mathrm{N},(\%)\end{array}$ & $\begin{array}{l}\text { Kisubi } \\
\mathrm{N},(\%)\end{array}$ & $\begin{array}{l}\text { Total } \\
\mathrm{N},(\%)\end{array}$ \\
\hline \multicolumn{2}{|l|}{$20-25$ years } & $14,(30.40)$ & $9,(29.00)$ & $23,(29.90)$ \\
\hline \multicolumn{2}{|l|}{$25-30$ years } & $21,(45.70)$ & $14,(45.20)$ & $35,(45.50)$ \\
\hline \multicolumn{5}{|l|}{ Respondents sex } \\
\hline \multicolumn{2}{|l|}{ Male } & $12,(26.10)$ & $9,(29.00)$ & $21,(27.30)$ \\
\hline \multicolumn{2}{|l|}{ Female } & $34,(73.90)$ & $22,(71.00)$ & $56,(72.70)$ \\
\hline \multicolumn{5}{|l|}{ Cadre of respondent } \\
\hline \multicolumn{2}{|l|}{ Nurse } & $39,(84.80)$ & $26,(83.90)$ & $65,(84.40)$ \\
\hline \multicolumn{2}{|l|}{ Physician } & $7,(15.20)$ & $5,(16.10)$ & $12,(15.60)$ \\
\hline \multicolumn{5}{|l|}{ The level of education } \\
\hline Cadre of respondent & Education & Entebbe & Kisubi & \\
\hline \multirow[b]{4}{*}{ Physician } & Certificate & $28,(71.80)$ & $20,(76.90)$ & $48,(73.80)$ \\
\hline & Diploma & $9,(23.10)$ & $6,(23.10)$ & $15,(23.10)$ \\
\hline & Degree & $2,(5.10)$ & $0,(0.00)$ & $2,(3.10)$ \\
\hline & Degree & $7,(58.30)$ & $5(41.70)$ & $12,(100.00)$ \\
\hline \multicolumn{5}{|c|}{ Length of time respondent has been practicing } \\
\hline cadre & Length of time & Entebbe & Kisubi & \\
\hline \multirow[t]{3}{*}{ Nurse } & $1-3$ years & $24,(61.50)$ & $15,(57.70)$ & $39,(60.00)$ \\
\hline & $4-6$ years & $11,(28.20)$ & $9,(34.60)$ & $20,(30.80)$ \\
\hline & 7 years and more & $4,(10.30)$ & $2,(7.70)$ & $6,(9.20)$ \\
\hline \multirow[t]{3}{*}{ Physician } & 1- 3 years & $2,(28.60)$ & $1,(20.00)$ & $3,(25.00)$ \\
\hline & 4-6 years & $1,(14.30)$ & $1,(20.00)$ & $2,(16.70)$ \\
\hline & 7 years and more & $4,(57.10)$ & $3,(60.00)$ & $7,(58.30)$ \\
\hline
\end{tabular}


Majority of nurses in the two hospitals, 39 (60.0\%), had practiced nursing care for between 1-3 years. Only $6(9.2 \%)$ of nurses had more than 7 years' experience. However, majority of the physicians, $7(58.3 \%)$, in both hospitals had practiced for a period of 7 and more years.

\section{Types of medical error reporting systems}

About two thirds of respondents in Kisubi hospital, 20
$(64.5 \%)$ reported that a medical error reporting system existedcomparedtoonlyathird, 14(30.40\%) in Entebbe hospital. However, upon observation, an incidence reporting book was present at Kisubi hospital while no such system was observed in Entebbe hospital. Still, majority of the respondents, $59(76.6 \%)$, believed that reporting medical errors reporting was mandatory, (table 2).

Table 2. Medical error reporting systems in the hospitals

\begin{tabular}{|l|l|l|l|}
\hline \multicolumn{4}{|l|}{ Hospital has a medical error reporting system } \\
\hline & $\begin{array}{l}\text { Entebbe } \\
\text { N, }(\%)\end{array}$ & $\begin{array}{l}\text { Kisubi } \\
\text { N, (\%) }\end{array}$ & $\begin{array}{l}\text { Total } \\
\text { N, }(\%)\end{array}$ \\
\hline Yes & $14,(30.40)$ & $20,(64.50)$ & $34,(44.20)$ \\
\hline No & $32,(69.60)$ & $11,(35.50)$ & $43,(55.80)$ \\
\hline \multicolumn{4}{|l}{} \\
\hline Mype of the medical error reporting system \\
\hline Voluntary & $40,(87.00)$ & $19,(61.30)$ & $59,(76.60)$ \\
\hline
\end{tabular}

Types of medical errors that occurred in the hospitals

A medical error was defined as "the failure of a planned action to be completed as intended or the use of a wrong plan to achieve an aim among other things, problems in practice, products, procedures and systems, (The Institute of Medicine, 1999).

More than half of the respondents, 41(53.2\%), reported that medical errors occurred,(table2). However, more respondents in Kisubi hospital, 16(51.6\%) believed medical
Errors did not occur as compared to 20(43.5\%) in Entebbe hospital. The belief that few medical errors occurred in Kisubi hospital could indicate a higher level of patient safety practices which could be attributed to awareness created by the voluntary incidence reporting system. About 33 (42.9\%) respondents reported occurrence of overdoses in the two hospitals, followed prescription errors, 27(35.1\%). Other errors reported included: near misses,9(11.7), adversedrugreactions $6(7.8 \%)$ and careless handling of patients $2(2.6 \%)$, (table 3$)$.

Table 3. Types of Medical errors occurring

\begin{tabular}{|c|c|c|c|}
\hline \multirow[t]{3}{*}{ Medical errors occur } & $\begin{array}{l}\text { Entebbe } \\
N,(\%)\end{array}$ & $\begin{array}{l}\text { Kisubi } \\
\text { N, (\%) }\end{array}$ & $\begin{array}{l}\text { Total } \\
\mathrm{N},(\%)\end{array}$ \\
\hline & $26,(56.50)$ & $\begin{array}{l}15, \\
(48.40)\end{array}$ & $41,(53.20)$ \\
\hline & $20,(43.50)$ & $\begin{array}{l}16, \\
(51.60)\end{array}$ & $36,(46.80)$ \\
\hline \multicolumn{4}{|c|}{ Type of medical errors occurring in the hospitals } \\
\hline Prescription errors & $16,(34.80)$ & $\begin{array}{l}11, \\
(35.50)\end{array}$ & $27,(35.10)$ \\
\hline Overdose & $19,(41.30)$ & $\begin{array}{l}14, \\
(45.20)\end{array}$ & $33,(42.90)$ \\
\hline Near misses & $6,(13.00)$ & $3,(9.70)$ & 9, (11.70) \\
\hline Adverse reactions & $4,(8.70)$ & $2,(6.50)$ & $6,(7.80)$ \\
\hline Careless handling of a patient & $1,(2.20)$ & $1,(3.20)$ & $2,(2.60)$ \\
\hline
\end{tabular}




\section{Knowledge and attitude towards medical error re- porting}

Slightly less than half, 29(44.6\%) of nurses and more than half, $7(58.3 \%)$, of physicians believed that reporting medical errors is a necessary medical obligation. Health workers in Kisubi hospital portrayed a better attitude towards medical error reporting as compared to Entebbe hospital. More than two thirds of respondents from Kisubi hospital, 18(69.2\%) nurses and 4(80.0\%) physicians, considered it a medical obligation as compared to $11(28.2 \%)$ nurses and 3(42.9\%) physicians in Entebbe hospital. Two thirds of nurses, $40(64.6 \%)$, dint know how to report medical errors while two thirds, $8(66.7 \%)$, of physicians knew how to report a medical error. About two thirds of nurses, 42, (64.6\%) and most physicians, 6(50\%) would not report a medical error if they were ever responsible.

\section{Policy related factors}

About two thirds, 41(63.1\%), of nurses and three quarters, $9(75.0 \%)$, of physicians were not aware of any hospital policy on medical error reporting. Still, majority, $57(87.7 \%)$, of nurses and, $10(83.3 \%)$, physicians believed that hospital policies do not affect medical error reporting system. More than half, 36(55.4\%), of nurses, and two thirds, $8(66.7 \%)$, of physicians had ever had opportunities for training on patient safety, (table 4).

Table 4. Factors influencing medical error reporting

\begin{tabular}{|c|c|c|c|c|}
\hline \multicolumn{5}{|c|}{ Knowledge, Attitude \& Perceptions } \\
\hline \multicolumn{2}{|c|}{ Reporting medical errors is a medical obligation } & $\begin{array}{l}\text { Entebbe } \\
N,(\%)\end{array}$ & $\begin{array}{l}\text { Kisubi } \\
N,(\%)\end{array}$ & $\begin{array}{l}\text { Total } \\
\mathrm{N},(\%)\end{array}$ \\
\hline \multirow[t]{3}{*}{ Nurse } & Yes & $11,(28.20)$ & $18,(69.20)$ & $29,(44.60)$ \\
\hline & No & $12,(30.80)$ & $8,(30.80)$ & $20,(30.80)$ \\
\hline & No response & $16,(41.00)$ & $0,(0.00)$ & $16,(24.60)$ \\
\hline \multirow[t]{3}{*}{ Physician } & Yes & $3,(42.90)$ & $4,(80.00)$ & $7,(58.30)$ \\
\hline & No & $3,(42.90)$ & $1,(20.00)$ & $4,(33.30)$ \\
\hline & No response & $1,(14.30)$ & $0,(0.00)$ & $1,(8.30)$ \\
\hline \multicolumn{5}{|c|}{ Knows how to report a medical error } \\
\hline \multirow[t]{2}{*}{ Nurse } & Yes & $12,(30.80)$ & $11,(42.3)$ & $23,(35.40)$ \\
\hline & No & $27,(69.20)$ & $15,(57.70)$ & $42,(64.60)$ \\
\hline \multirow[t]{2}{*}{ physician } & Yes & $5,(71.40)$ & $3,(60.00)$ & $8,(66.70)$ \\
\hline & No & $2,(28.60)$ & $2,(40.00)$ & $4,(33.30)$ \\
\hline \multicolumn{5}{|c|}{ If ever responsible for an error reported it himself/herself } \\
\hline \multirow[t]{3}{*}{ Nurse } & Yes & 7, (17.90) & $6,(23.10)$ & $13,(20.00)$ \\
\hline & No & $28,(71.80)$ & $14,(53.80)$ & $42,(64.60)$ \\
\hline & No response & 4, (10.30) & $6,(23.10)$ & $10,(15.40)$ \\
\hline \multirow[t]{3}{*}{ Physician } & Yes & $3,(42.90)$ & $1,(20.00)$ & 4, (33.30) \\
\hline & No & $2,(28.60)$ & $4,(80.00)$ & $6,(50.00)$ \\
\hline & No response & $2,(28.60)$ & $0,(0.00)$ & $2,(16.70)$ \\
\hline \multicolumn{5}{|c|}{ The law protects a health worker who reports a medical error } \\
\hline \multirow[t]{2}{*}{ Nurse } & Yes & $5,(12.80)$ & $10,(38.50)$ & $15,(23.10)$ \\
\hline & No & $34,(87.20)$ & $16,(61.50)$ & $50,(76.90)$ \\
\hline Physician & No & 7, (100.00) & $5,(100.00)$ & $12,(100.00)$ \\
\hline \multicolumn{5}{|c|}{ Explanation of whether the law protects a health worker } \\
\hline \multirow[t]{5}{*}{ Nurse } & Cannot be arrested & $3,(7.70)$ & 4, (15.40) & 7, (10.80) \\
\hline & Can be arrested & $8,(20.50)$ & $3,(11.50)$ & $11,(16.90)$ \\
\hline & Be prosecuted & $20,(51.30)$ & $11,(42.30)$ & $31,(47.70)$ \\
\hline & No action & $3,(7.70)$ & $2,(7.70)$ & $5,(7.70)$ \\
\hline & Some form of action & $5,(12.800$ & $6,(23.10)$ & $11,(16.90)$ \\
\hline \multirow[t]{3}{*}{ Physician } & Can be arrested & $2,(28.60)$ & $1,(20.00)$ & $3,(25.00)$ \\
\hline & Be prosecuted & $2,(28.60)$ & $3,(60.00)$ & $5,(41.70)$ \\
\hline & Some form of action can be taken & $3,(42.90)$ & $1,(20.00)$ & $4,(33.30)$ \\
\hline
\end{tabular}


Legal consequences of reporting a medical error.

All physicians, 12 (100\%)andthreequarters,50(76.9\%), of nurses believed the law does not protect a health worker who reported a medical error. About $5(41.7 \%)$ of physicians were of the opinion that medical error reporting would result in prosecution, or, $4(33.3 \%)$, some form of punitive action. On the other hand, 31(47.7\%) and $11(16.9 \%)$ nurses believed it would result in prosecution or some form of punitive action respectively.
Measures for improving medical error reporting.

More than half, 35(53.8\%), of the nurses, ranked 'Not punishing health workers who report medical errors' as the important measure to encourage medical error re porting. On the other hand, 5(41.7\%), ranked 'Training on medical error reporting' as the most important measure to improve medical error reporting, (table 5).

Table 5. Measures to improve medical error reporting

\begin{tabular}{|l|l|l|l|l|}
\hline Measures to improve medical error reporting \\
\hline \multirow{4}{*}{ Cadre } & Measure & $\begin{array}{l}\text { Entebbe } \\
\mathrm{N},(\%)\end{array}$ & $\begin{array}{l}\text { Kisubi } \\
\mathrm{N},(\%)\end{array}$ & $\begin{array}{l}\text { Total } \\
\mathrm{N},(\%)\end{array}$ \\
\hline \multirow{5}{*}{ Nurse } & Medical error alert at OPD & $5,(12.80)$ & $2,(7.70)$ & $7,(10.80)$ \\
\cline { 2 - 5 } & $\begin{array}{l}\text { Nurses, pharmacists and physicians to } \\
\text { report medical errors }\end{array}$ & $0,(0.00)$ & $1,(3.80)$ & $1,(1.50)$ \\
\cline { 2 - 5 } & Error information sheets at OPD & $2,(5.10)$ & $0,(0.00)$ & $2,(3.10)$ \\
\cline { 2 - 5 } & Training on error reporting & $11,(28.20)$ & $9,(34.60)$ & $20,(30.80)$ \\
\cline { 2 - 5 } & $\begin{array}{l}\text { Not punishing health workers who } \\
\text { Physician }\end{array}$ & $21,(53.80)$ & $\begin{array}{l}14, \\
(53.80)\end{array}$ & $35,(53.80)$ \\
\cline { 2 - 5 } & report medical errors & $1,(14.30)$ & $1,(20.00)$ & $2,(16.70)$ \\
\cline { 2 - 5 } & $\begin{array}{l}\text { Nurses, pharmacists and physicians to } \\
\text { report medical errors }\end{array}$ & $0,(0.00)$ & $1,(20.00)$ & $1,(8.30)$ \\
\cline { 2 - 5 } & Error information sheets at OPD & $0,(0.00)$ & $1,(20.00)$ & $1,(8.30)$ \\
\cline { 2 - 5 } & Training on error reporting & $4,(57.10)$ & $1,(20.00)$ & $5,(41.70)$ \\
\cline { 2 - 5 } & $\begin{array}{l}\text { Not punishing health workers who } \\
\text { report medical errors }\end{array}$ & $2,(28.60)$ & $1,(20.00)$ & $3,(25.00)$ \\
\hline
\end{tabular}

\section{Discussion}

The two hospitals had younger health workers in the two cadres, the young staff is preferred possibly because they are more productive than those who are old, although the general situation of a low life expectancy for Ugandans may contribute to this. The age groups correspond with other findings ${ }^{6}$. Females constitute the bulk of health workers in the hospitals, and concurs with another study ${ }^{7,8,9}$. In other parts of the world that the position of nurses takes the biggest proportion of hospital staff, ${ }^{10,6}$. Medical errors occurred in the two hospitals and most

nurses and physicians were aware that they occurred. Majority of nurses and physicians in the two hospitals suggested that over doses were the most prevalent of the errors followed by prescription errors. The occurrence of these errors have been documented in hospitals in Central Uganda ${ }^{11}$ and are common in Sub-SaharanAfrica, ${ }^{12}$. The occurrence of medical errors in the hospital sets a basis for establishing a standard error reporting system in the two hospitals. The World Health Organization, describes two types of systems: the Accountability System-a mandatory reporting system which is restricted to a list of defined serious events such as unexpected death, transfusion reaction and wrong site surgery; and the Voluntary Reporting System whose objectives are to identify errors and hazards and

to investigate them to uncover underlying system failures with a goal of redesigning the system to reduce the likelihood of patient injury ${ }^{13}$. 
The two hospitals lacked a medical error reporting system. This is in agreement with other recent findings, ${ }^{11}$. This lack of a medical error reporting system will continue prohibiting health workers from learning from mistakes and improving patient safety. The efforts by the National Drug authority through the National pharmacovigilance center may not be sufficient at ensuring reporting as it only concentrates on adverse drug reactions leaving out the other medical errors, such as wrong medical procedures, ${ }^{14}$. Many countries in Sub-Saharan Africa, including Uganda face similar challenges, ${ }^{12,15,16}$. However, measures need to be put in place to ensure establishment of medical error reporting systems to record, identify and record medication-related incidents occurring in hospitals ${ }^{17,3}$. Findings from observational checklist detailed attempts at establishing a medical error reporting system in Kisubi hospital through the error reporting book. This is a Catholic funded mission hospital and is in line with attempts by Uganda Catholic Medical Bureau goals of improving patient safety, ${ }^{18}$. It was unfortunate that the voluntary error reporting system in Kisubi hospital had stopped operating by the time of this study. This could possibly be due to other suggested reasons including fear of intimidation and legal consequences. This is a confirmation of the factors identified by the National Academy for state Health Policy in its report in which it concluded that protection from legal consequences is key to voluntary medical error reporting ${ }^{19}$.

On the other hand, there was no evidence of error reporting system in Entebbe hospital. This could be due to challenges related to error reporting since even in organizations with a culture of safety, creating a non-punative environment is a work in progress, ${ }^{20}$. This can be improved by having leadership committed to patient safety; eliminating the punitive culture and institutionalizing a culture of safety; increasing reporting of near misses; providing timely feedback and follow up actions and improvements to avert future errors; and having a multi-disciplinary approach to reporting is very important in improving patient safety ${ }^{14}$.

Kisubi hospital attempted to establish a voluntary medical error reporting system, which corresponds with a study which suggested that the systems can either be mandatory orvoluntary, ${ }^{21}$. Although there were no formal medical error reporting systems, health workers tended to attempt to share their experiences. This was reflected by some respondents saying they would "report to a senior in charge". This concurs with findings that health workers tended to invoke informal processes in which errors are shared with other colleagues or with a nursemanager, ${ }^{22,23}$. Although informal reporting could be a positive under- taking (i.e. "better than nothing"), it perhaps is more worrisome because it cultivates a false sense of safety. Such informal reporting, such as: "reporting to a senior in charge" and "recording somewhere" may be a way to discharge personal responsibility without threatening power relationships. Telling one person or a group of colleagues informally does not promote awareness and prevention across the system.

The study revealed occurrence of medical errors. Among the medication errors include: overdoses, prescription errors and adverse drug reactions. This concurs with other recent findings that reported occurrence of medical errorsinUganda ${ }^{11,12}$. It also follows the global occurrence of medical errors elsewhere ${ }^{24}$ and are similartoothers ${ }^{25}$. In addition, respondents reported occurrence of prescription errors which concurs with other findings, ${ }^{25,26}$ who also reported that prescription errors occur in hospitals. They are also supported by studies done by others, ${ }^{27,28,29,30}$. Respondents also alluded to the existence of adverse drugreactionsinlinewithotherfindings, ${ }^{31,32,33,34,35}$. The two hospitals dint have policies guiding medical error reporting contrary to recommendation that institutions should develop policy which encourages transition of an institution to a culture of safety, elimination blame and the pressure of a punitive environment so as to increase the likely of error reporting ${ }^{36}$.

Most nurses did not think did they think hospital policies can prevent medical error reporting since merely changing policy

Would not influence error reporting. Majority of the respondents were of the opinion that the hospital has a role in establishing medical error reporting system.Hospitalsshouldbeproactiveinpromotingpatientsafetyandtakealeadingroleinestablishingmedical error reporting systems ${ }^{17}$.

Nurses and physicians fear reporting medical errors due to fear of punishment and lack of confidentiality. The fears among health workers include; legal consequences, fear of losing a job, fear of punishment and fear of intimidation. This is worrying since all physicians and nurses swear to uphold the dignity of life in the hypocritic oath, ${ }^{37}$. 
Nurses and physicians expressed their fear of prosecution if they reported medical errors. This is in line with a study which reported that "Physicians say their worst fear about errors included law suits", 38 . Health care workers fear punishment and litigation ${ }^{11}$ and a non-punitive legislation that protects those who report medical errors should be enacted to encourage medical errors reporting $^{12}$. This is in agreement with findings in Uganda that health workers fear punishment bysupervisorsandterminationofcontracts ${ }^{11}$. These findings also concur with others which report that lack of confidentiality, is a barrier which makes physicians hesitate to disclose errors ${ }^{17,39,40}$ Reports that many health workers had negative attitude towards reporting errors because of the fear of the repercussions when they reported. Such repercussions included being blamed for the error, punishment given to those who commit errors and fear of losing their jobs. Fears of reprisal and punishment have been reported elsewhere to lead to a norm of silence as those who make errors fear disciplinary procedures and do not want to report hem $^{41,42}$. There is a lot of evidence discouraging

The punishment of health care workers for reporting medical errors ${ }^{43,38,44}$.

Reporting medical errors is believed to be a medical obligation by most nurses and physicians. They believe it is an obligation to identify, report errors and improve patient safety. This is in line with other studies which recommend that the systems should help health workers to identify, record and improve reporting of medication-related incidents occurring in hospitals and hence safety ${ }^{11,17}$. However, most nurses and physicians in the two hospitals would be reluctant to report a medical error if it ever occurred under their watch. This is in line with other findings that most physicians are reluctant to participate in medication error reporting36. Studies have shown that nurses were concerned about anonymity and fear of law suits ${ }^{17}$. The World Alliance for Patient Safety Forward Programme ${ }^{13}$ recommended that reporting must be safe and individuals who report incidents must not be punished or suffer other ill-effects from reporting.

Nurses and physicians work in an environment with a culture of blame and punishment, and as such they may not report all errors, primarily because they fear punishment and the long-held tradition in health care: the "name you blame you, shame you"mantra, ${ }^{42}$. Establishment of a blame free and non-punitive environment would advance medical error reporting ${ }^{45,39}$. From the findings in this study, health workers suggest an environment where they are not punished when they report medical errors. Further, the punitive culture should be eliminated. This agrees with other studies ${ }^{11,14,46,47,3,43}$.

\section{Implications of the study findings For policy makers}

It is evident that medical errors are occurring in Ugandan hospitals and policies and systems for their reporting and ensuring patient safety do not exist. The hospital administration of the hospitals should ensure establishment of a non-punitive environment on medical error reporting. Legislation concerning medical errors should be drafted, discussed and passed to encourage patient safety practices.

For measures to encourage medical error reporting The human resource department should consistently train staff on medical errors and their reporting. It should also place conducive environment which ensures feedback and corrective measures as regards patient safety. Additionally, means of reporting within the hospital premises should be designated for medical error reporting.

\section{Conclusion}

The study concludes that medical errors exist in the two hospitals. There were neither policies nor systems to report such errors in both the private and public hospital. Health worker related factors such as; their knowledge, and attitudes towards medical error reporting is a big impediment towards improving reporting. These gaps provide room for complacency without benchmarks for improving patient safety. The two hospitals have no policies for reporting medical errors. The hospitals have not taken a leading role in establishing system store port medical errors. Physicians and nurses may not report medical errors for fear of losing a job and legal consequences Other personal barriers include lack of knowledge about medical error reporting, fear of intimidation, and lack of confidentiality were identified as important barriers to medical error reporting. 


\section{Study limitations}

Whereas the findings of this study may be beneficial to the hospitals under study and the nation generally, generalization of the findings may not be applicable to all the hospitals in Uganda considering the few hospitals sampled. There were also the inherent shortcomings of sampling as a method of selecting study population. This can be improved by using a system involving more study participants.

\section{Recommendations}

The study recommends that all stakeholders including government and the hospital administration should enact friendly and non-punitive

Policies to encourage and guide medical error reporting. The hospitals should be encouraged and facilitated to establish medical error reporting systems.

There is need for enactment of legislation that protects health care workers when reporting medical errors and lead to improved patient safety.

Health workers should be trained on various aspects of patient safety especially on how to report a medical error. Hospitals should continuously encourage an environment where health care workers relate well with colleagues and feel free to discuss problems encountered in their work.

\section{Conflict of interest}

None declared.

\section{References}

1. Programme F. Alliance for Patient Safety. Forward program. October [Internet]. 2005;33.

2. J J E van Everdingen. Find a copy in the library Patient safety toolbox : instruments for improving safety in health care organisations [Internet]. Houten: Bohn Stafleu van Loghum; 2007. Available from: https:// www.worldcat.org/title/patient-safety-toolbox-instruments-for-improving-safety-in-health-care-organisations/oclc/150239520?referer=di\&ht=edition

3. Expert Group on Safe Medication Practices. Creation of a better medication safety culture in Europe : Building up safe medication practices. Counc Eur [Internet]. 2006;275. Available from: https://www.edqm.eu/medias/fichiers/Report_2006.pdf

4. Terzibanjan A, Laaksonen R, Weiss M, Airaksinen M, Wuliji T, Kingdom U, et al. Medication error reporting systems - lessons learnt. Int Pharm Fed. 2007;(Table 1):1-
7.

5. Mrayyan MT, Shishani K, Al-Faouri I. Rate, causes and reporting of medication errors in Jordan: Nurses' perspectives. J Nurs Manag. 2007;15(6):659-70.

6. Opollo JG, Opollo DA, Gray J SL. Conducting international nursing research: challenges and opportunities. Nurse Res [Internet]. 2014;22(2):29-33. Available from: https://www.ncbi.nlm.nih.gov/pubmed/25423939

7. Lutwama GW, Roos JH, Dolamo BL. A descriptive study on health workforce performance after decentralisation of health services in Uganda. Hum Resour Health. 2012;10:1-10.

8. Amy Hagopia, Batenganya Moses, Paula Tavrow, Samuel Luboga \& SB. Incentives and Barriers to implementing National Hospital Standards in Uganda. Int J Qual Healthc. 2009;21(6):421-6.

9. Republic THE. QIF\&Strategic Plan 2015_2020_June. 2019;(June 2016).

10. Joolaee S, Hajibabaee F, Peyrovi H, Haghani H, Bahrani $\mathrm{N}$. The relationship between incidence and report of medication errors and working conditions. Int Nurs Rev. 2011;58(1):37-44.

11. Anguyo Robert D SPK, A M, Stella RN. Common Medical Errors and Error Reporting Systems in Selected Hospitals of Central Uganda. Int J Public Heal Res [Internet]. 2015;3(5):292-9. Available from: https:// www.academia.edu/31145039/Common_Medical_Errors_and_Error_Reporting_Systems_in_Selected_Hospitals_of_Central_Uganda

12. Kiguba R, Waako P, Ndagije HB, Karamagi C. Medication Error Disclosure and Attitudes to Reporting by Healthcare Professionals in a Sub-Saharan African Setting: A Survey in Uganda. Drugs-Real World Outcomes. 2015;2(3):273-87.

13. WHO: World Alliance for Patient Safety. World Health Organization. World Alliance For Patient Safety: WHO draft guidelines for advance event reporting and learning systems. From information to action. WHO Reports [Internet]. 2005; Available from: https://apps.who.int/iris/ bitstream/handle/10665/69797/WHO-EIP-SPO-QPS05.3-eng.pdf? sequence $=1 \&$ is Allowed $=y$

14. Mary Force;Linda Deering;John Hubbe;Marcy Andersen;Barbara Hagemann;Michelle Cooper-Hahn;William Peters; Effective Strategies to Increase Reporting of Medication Errors in Hospitals. JONA J Nurs [nternet]. 2006;36(1):34-41. Available from: https://insights.ovid. $\mathrm{com} /$ pubmed?pmid=16404199

15. Enwere O. Okezie FO. Adverse drug reactions re- 
porting by physicians in Ibadan, Nigeria. 2008;17:51722. Available from: https://onlinelibrary.wiley.com/ doi/pdf/10.1002/pds.1597?casa_token=Y8013Cq94zoAAAAA:L3yoHr6vlJ7o0xOrGHrkASQ7j33rcYGwJ1MmXa450qNZ7Ou1ye6fyz2vuRVB4_rKYwU8izGb2U6yE9Jcow

16. Oshikoya KA, Awobusuyi JO. Perceptions of doctors to adverse drug reaction reporting in a teaching hospital in Lagos, Nigeria. BMC Clin Pharmacol. 2009;9:1-8.

17. Claudia Uribe;Sharon Schweikhart;Dev Pathak;Evaluation Studies;Gail Marsh. Perceived Barriers to Medical-Error Reporting: An Exploratory Investigation. J Healthc Manag [Internet]. 2002;47(4):263-80. Available from: https://insights.ovid.com/crossref?an=00115514-200207000-00009

18. M L. Uganda Catholic Medical Bureau Bulletin [Internet]. 2011. Available from: https://www.ucmb.co.ug/ files/UCMBdocs/Reports/ARTICLES/UCMB Annual Report 2012 - Final.pdf

19. Rosenthal J, Wood R, Foundation J. Defining Reportable Adverse Events : A Guide for States Tracking Medical Errors. Natl Acad State Heal Policy [Internet]. 2003;(March). Available from: https://nashp.org/wp-content/uploads/ sites/default/files/defining_adverse_events.pdf

20. Buerhaus PI. Lucian leape on patient safety in U.S. hospitals. J Nurs Scholarsh. 2004;36(4):366-70.

21. Weissman JS, Annas CL, Epstein AM, Schneider EC, Clarridge B, Kirle L, et al. Error Reporting and Disclosure Systems. JAMA [Internet]. 2005;293(11):1359-66.

22. Sherry Espin, Glenn Regehr, Wendy Levinson, G. Ross Baker CB\& LL. Factors Influencing Perioperative Nurses' Error Reporting Preferences. AORNJ [Internet]. 2007;85(3):527-43. Available from: https://aornjournal.onlinelibrary.wiley.com/doi/pdf/10.1016/S00012092\%2807\%2960125-2

23. Garbutt J, Waterman AD, Kapp JM, Dunagan WC, Levinson W, Fraser V, et al. Lost opportunities: How physicians communicate about medical errors. Health Aff. 2008;27(1):246-55.

24. Milstein A, Galvin RS, Delbanco SF, Salber P, Buck CR. Improving the safety of health care: the leapfrog initiative. Eff Clin Pract. 2000;3(6):313-6.

25. Flynn EA, Barker KN, Carnahan BJ. National observational study of prescription dispensing accuracy and safety in 50 pharmacies. J Am Pharm Assoc. 2003;43(2):191200.

26. Dean B, Schachter M, Vincent C, Barber N. Prescrib- ing errors in hospital inpatients: Their incidence and clinical significance. Qual Saf Heal Care. 2002;11(4):340-4. 27. Lucian L. Leape. Error in Medicine. JAMA - J Am Med Assoc [Internet]. 1994;272(23):1851-7. Available from: https://jamanetwork.com/journals/jama/article-abstract $/ 384554$

28. Franklin BD, Reynolds M, Shebl NA, Burnett S, Jacklin A. Prescribing errors in hospital inpatients: A three-centre study of their prevalence, types and causes. Postgrad Med J. 2011;87(1033):739-45.

29. Alrwisan A, Ross J WD. Medication incidents reported to an online incident reporting system. Eur J Clin Pharmacol [nternet]. 2011;67(5):527-32. Available from: https://www.ncbi.nlm.nih.gov/pubmed/21240481

30. Julius Cuong, Monica S. Aswani, Michael Rosen, HeeWon Lee, Matthew Huddle, Kristina Weeks and PJP. Reducing Medical Errors and Adverse Events. Annu Rev Med [Internet]. 2011;63:447-63. Available from: https://www.annualreviews.org/doi/pdf/10.1146/annurev-med-061410-121352

31. Barach P, Small SD. Reporting and preventing medical mishaps: Lessons from non-medical near miss reporting systems. Br Med J. 2000;320(7237):759-63.

32. Dyer C. Doctor sentenced for manslaughter of leukaemia patient. BMJ [Internet]. 2003;327(7417):697. Available from: https://www.ncbi.nlm.nih.gov/pmc/articles/PMC200830/pdf/bmj3270697a.pdf

33. Aronson JK, Henderson G, Webb DJ, Rawlins MD. A prescription for better prescribing. $\mathrm{Br}$ Med J. 2006;333(7566):459-60.

34. Brennan TA, Leape LL, Laird NM, Hebert L, Localio AR, Lawthers AG, et al. Incidence of adverse events and negligence in hospitalized patients: results of the Harvard Medical Practice Study I. 1991. Qual Saf Health Care. 2004;13(2):370-6.

35. M Zegers, M C de Bruijne, C Wagner, L H F Hoonhout, R Waaijman, M Smits, F A G Hout, L Zwaan, Christiaans-Dingelhoff, D R M Timmermans, P P Groenewegen $G$ van der W. Adverse events and potentially preventable deaths in Dutch hospitals: results of a retrospective patient record review study. BMJ Qual Saf [Internet]. 2009;18(4). Available from: https:/ qualitysafety. bmj.com/content/18/4/297

36. Wolf ZR, Hughes RG. Chapter 35 . Error Reporting and Disclosure. In: Patient Safety and Quality: An Evidence-Based Handbook for Nurses. 2008. p. 1-47.

37. Sritharan K, Russell G, Fritz Z, Wong D, Rollin M, 
Dunning J, et al. Medical oaths and declarations. BMJ. 2001;323(7327):1440-1.

38. Gallagher TH, Waterman AD, Ebers AG, Fraser VJ, Levinson W. Patients' and Physicians' Attitudes Regarding the Disclosure of Medical Errors. J Am Med Assoc. 2003;289(8):1001-7.

39. Kaldjian LC, Jones EW, Rosenthal GE, Tripp-Reimer T, Hillis SL. An Empirically Derived Taxonomy of Factors Affecting Physicians' Willingness to Disclose Medical Errors. J Gen Intern Med. 2006;0(0):060721075157049-??? 40. R Lawton DP. Barriers to incident reporting in a healthcare system. Qual Saf Heal Care [Internet]. 2002;11(1):7. Available from: https://www.ncbi.nlm.nih. gov/pmc/articles/PMC1743585/pdf/v011p00015.pdf 41. Maxfield, D. Grenny, J., McMillan, R., Patterson, K., Switzler A, (Firm) V. Silence kills: The seven crucial conversations for healthcare. Am Assoc Crit Care Nurses [nternet]. 2005;18. Available from: http://scholar. google.com/scholar?hl=en\&btnG=Search\&q=intitle:Silence+Kills:+The+Seven+Crucial+Conversations+for + Healthcare\#0

42. Steven M.Handler, David A. Nace, Stephanie A.Studenski DBF. Medication error reporting in long term care. Am J Geriatr Pharmacother. 2004;2(3):190-6.
43. Wakefield DS, Wakefield BJ, Borders T, Uden-Holman T, Blegen M VT. Understanding and comparing differences in reported medication administration error rates. $A m$ J Med Qual [nternet]. 1999;14(2):73-80. Available from: https://www.ncbi.nlm.nih.gov/pubmed/10446668 44. Harper ML, Helmreich RL. Identifying Barriers to the Success of a Reporting System. Adv Patient Saf From Res to Implement (Volume 3Implementation Issues) [Internet]. 2005;167-80. Available from: http://www.ncbi. nlm.nih.gov/pubmed/21249983

45. David F. Lehmann. Every Error a Treasure: Improving Medication Use with a Nonpunitive Reporting System. Jt Comm J patient Saf [Internet]. 2007;33(7):401-7. Available from: https://www.jointcommissionjournal. com/article/S1553-7250(07)33046-8/fulltext

46. Evans SM, Berry JG, Smith BJ, Esterman A, Selim P, O'Shaughnessy J, et al. Attitudes and barriers to incident reporting: A collaborative hospital study. Qual Saf Heal Care. 2006;15(1):39-43.

47. Kim, Jeongeun, Kyungeh An, Minah Kang Kim SHY. Nurses' Perception of Error Reporting and Patient Safety Culture in Korea. West J Nurs Res [Internet]. 2007;29(7):827-44. Available from: https://journals. sagepub.com/doi/abs/10.1177/0193945906297370 